Generally we could classify our needs in three groups:

1. A high powered, multi-stage centrifugal pump. It should have some sort of shifting device to put the pump stages in parallel to give high volume at low pressure for filling tanks or pumping along the level, or shift the stages into series to provide very high pressure at low volumes for pumping uphill. As a suggestion, it should pump 200 gallons per minute at 30 lbs. pressure in the volume phase, and 10 gallons per minute at 600 lbs. pressure in the pressure stage. It should not weigh more than $90 \mathrm{lbs}$. so that two men can carry it to the water source.

2. A low-powered light-weight pump producing pressures in excess of $350 \mathrm{lbs}$. weighing not more than 35 lbs. Volumes should be kept low $(8-12 \mathrm{gpm})$ purposely. This is to be used on 300-gallon Harrodyke tanks, metal water tanks on colddeckers, sump holes, or wherever the water supply is limited.

3. A pump that is capable of pumping fire retardant chemical at least with a 400-foot head. This chemical (Sodium-Calcium-Borate) is very abrasive and to date there is no inexpensive pump that will successfully pump this suspension to adequate heights. fireline.

With these three types we should be able to meet all requirements on the

Knowing this we should no longer buy a pump merely because it is advertised as being "suitable for fighting fire." Instead we can purchase a unit that is tailor made to suit a specific purpose.

\title{
THE TOWILL PHOTO-CONTOUR MAP ${ }^{1}$
}

\section{By A. M. Nelson"}

There are many kinds of maps used in forestry ranging from unscaled sketches through mosaics to the standard conventional topographic map. The preparation of the detail of these maps is usually kept to a minimum to aid the map user to solve his immediate problems, and having such a map, it has served its purpose.

Today, however, the trend is to secure maps that have all possible detail plotted for operational uses. This is time consuming, and any interpretation of detail from the air photo is subject to the ability and judgement of the interpreter.

However, the Towill photo-contour map is a map which provides contours and all possible detail, the detail being added from a rectified photographic image. Therefore, contours and detail are at constant scale.

The advantage of such large-scale maps over conventional maps is that features and detail are not omitted; therefore, personnel using the photo-contour

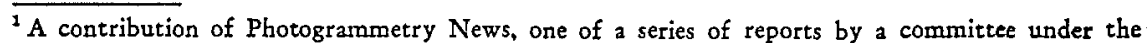
chairmanship of Mr. J. R. Collins, Forestal, Forestry and Engineering International Limited. "Vice-President, McElhanney Nelson Air Surveys Ltd., Vancouver, B.C.
} 
map will be able to find their position on the ground more rapidly, and because of constant scale it obviously has an advantage over mosaics.

In forestry, where mapping photogrammetrically is most difficult due to the dense overburden, the only conventional symbols that are feasible to plot are timber types, open swamps, open rock outcrops, etc., but having a photo image at scale the user will be able to recognize from the crown cover such points of detail that are impossible for an interpreter to plot.

The photo contour map can be produced showing contours, timber types, lot lines and any other detail that may be required such as boundaries or line work that is essential to the user.

The map is valuable for field navigation and, although it has not been used to any extent in Canada, it is felt that when this type of map is used in forestry, many other uses will evolve from them.

The advantages of the photo-contour map for forestry uses will be made known only when there have been sufficient maps employed in the industry.

The maps will not eliminate the forester, but will assist him in becoming more efficient in his work. Research is going on all the time and will eventually offer the ultimate in mapping.

Foresters can assist to a large degree in making known the problems to the author with their recommendations.

The photo-contour map was first produced by R. M. Towill Corporation, Ltd. in Hawaii, and is being used in many parts of the world today with great success in many other engineering fields.

\section{ANNUAL MEETING \\ PAPERS AND REPORTS ARE NOW AVAILABLE UPON REQUEST}

Publication of all material presented at the 1958 Annual C.I.F. Meeting will not be possible. Members interested should, therefore, obtain a set of papers from:

Mr. G. L. MILLER,

P.O. Box 1120,

Fredericton, N.B. 